\title{
Technical note: A closed chamber method to measure greenhouse gas fluxes from dry sediments
}

Lukas Lesmeister, Matthias Koschorreck

\section{Supplemental material}

5 Figure S1: Laboratory setup to test chamber sealing.

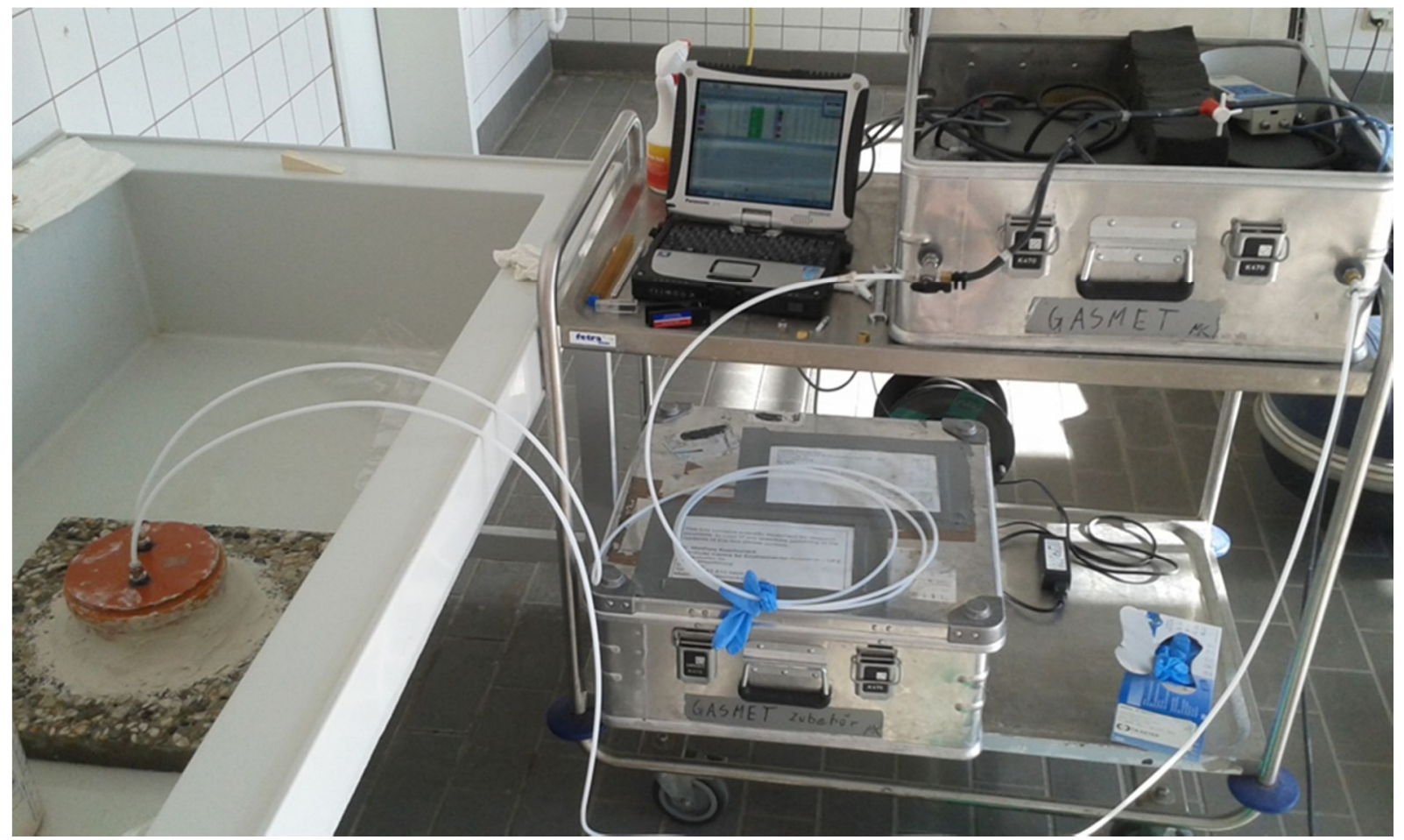


Figure S2: Field test sites.

Bridge soil site: near the shore of the river Elbe in

Magdeburg, Germany

(coordinates: $52^{\circ} 7.62^{\prime} \mathrm{N}$, $11^{\circ} 39.04^{\prime}$ O).

River sand site: Right shore (summer dry river bed) of the river Elbe in Magdeburg, Germany (coordinates: $52^{\circ} 7.92^{\prime} \mathrm{N}, 11^{\circ} 39.42^{\prime} \mathrm{O}$ ).

Shores of Rappbode reservoir in the Harz mountains in Saxony-Anhalt, Germany, slightly north-west from the Hassel pre-dam (coordinates: $51^{\circ} 43.83^{\prime} \mathrm{N}$, $10^{\circ} 52.63^{\prime} \mathrm{O}$ ).
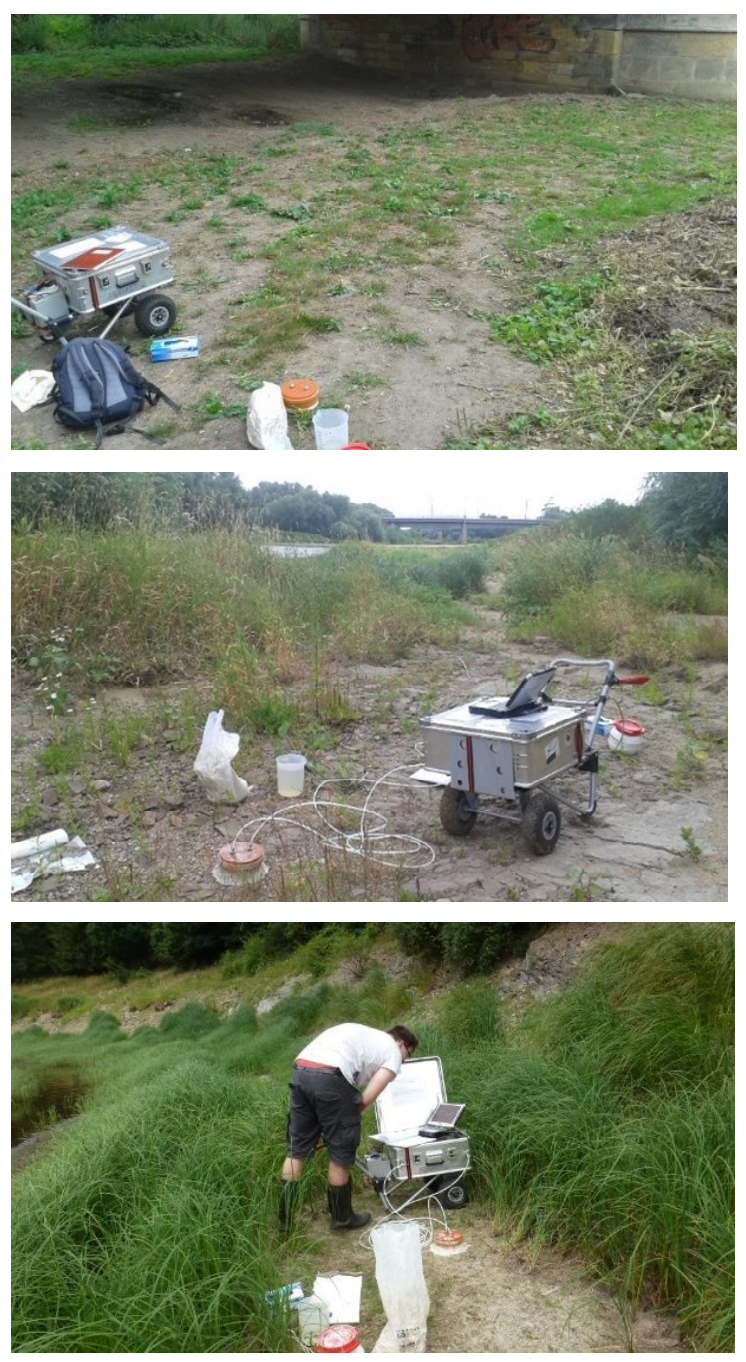

Figure S3: Sealing the chamber with clay.
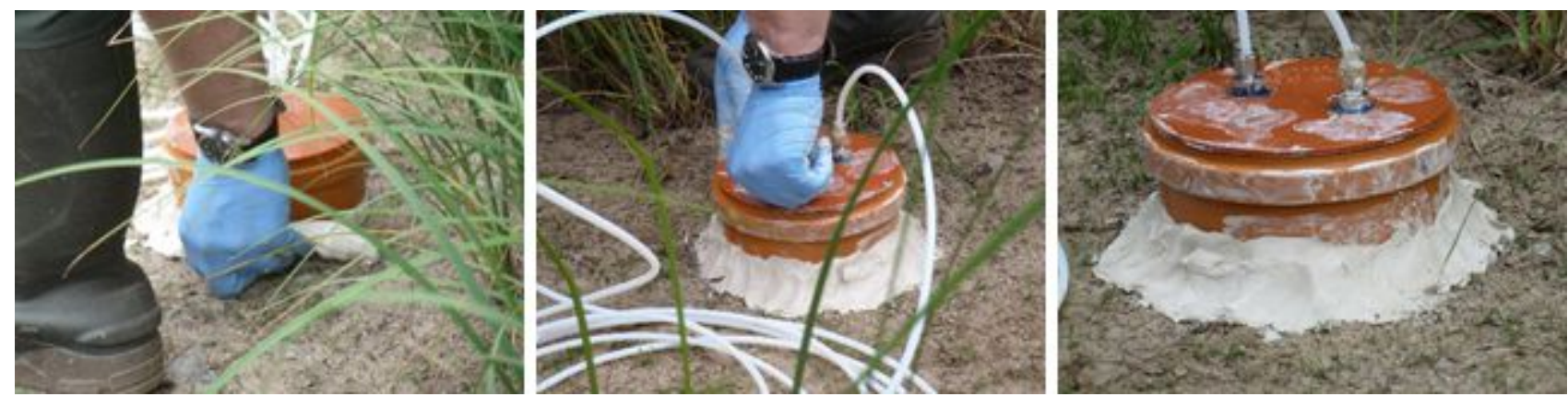